\title{
Physical and sports activity during the COVID-19 pandemic
}

\author{
GAETANO RAIOLA ${ }^{1}$, FELICE DI DOMENICO ${ }^{2}$ \\ ${ }^{1,2}$, University of Salerno, ITALY
}

Published online: February 28, 2021

(Accepted for publication February 22, 2021)

DOI:10.7752/jpes.2021.s1049

\begin{abstract}
The SARS-COVID 19 pandemic, which has hit the planet in recent times, in addition to changing daily life habits, also has negative repercussions on indoor exercise and sports, due to the social restrictions imposed by governments to address and contain the contagion. As a first response to this change in the social habits of practicing indoor physical activity in gyms, physical activity and sports professionals have developed innovative and original design ideas for outdoor training by proposing different physical disciplines for different classes of users. However, knowledge of the state of the art relating to the adaptations and opinions of physical activity and sports clients following the closure of indoor gyms is still poor. Considering that this knowledge differs from territory to territory by type of social and environmental context, the problem of the study is limited to the territory of interest and towards which the attention of indoor gym managers is directed. The chosen area is that of the municipality of Fisciano (province of Salerno) where the users of the Studio Zen gym are interested, which has about 100 customers. The aim of the study is to quantify the level of participation in outdoor training activities organized in compliance with the anti-COVID legislation, paying particular attention to the effects of constraints on physical and sports practice. The study was conducted using the Cluster Analysis methodology which, through the administration of a questionnaire drawn up with the Google Forms platform, collected data relating to the level of motor and sports practice before and after the closure of the indoor gyms. The data collected show that the outdoor training proposal in this study did not have a high level of participation for various reasons, both subjective and objective, which led the subjects to choose other training methods or decide not to perform any motor or sports activity.
\end{abstract}

Keywords: lockdown, outdoor training, wellness, athletic training, COVID 19

\section{Introduction}

In the era in which we live, the awareness that physical activity plays a central role in maintaining and recovering a good state of health and the relational and social functions of the individual is increasingly widespread (D'Elia et al , 2020), in addition to favouring motor learning mechanisms (Di Domenico et al., 2019; Raiola 2017, 2015, 2013) which favours the acquisition and consolidation of several skills, including tactics ones (Ceruso et al, 2019ab). Regular light-intensity physical activity translates into significant health benefits such as in elite athlete (Altavilla, 2020, D'Isanto, 2020, 2016, Sannicandro 2020, 2011, Sannicandro et al, 2015, 2017, 2008), as well as soccer athletes such as for the footballer (D'Elia et al, 2019, Izzo et al, 2020abc, 2019ab) while a sedentary lifestyle and other risk factors contribute to the development of chronic degenerative diseases, particularly cardiovascular (Altavilla et al, 2018; Both et al ., 2017) but also for extra use of smartphone (Aliberti et al, 2020).Motor activity, aimed at safeguarding and promoting psycho-physical well-being, is to be considered as a global intervention strategy that leads to the acquisition of lifestyles and behavioral skills that guide the individual to take responsibility towards safeguarding their own health and collective. Sporting activity, on the other hand, aims at improving the athlete's performance skills determined by hereditary or acquired factors (D'Isanto et al., 2019) with well-structured and periodization of training programs. The SARS-COVID 19 pandemic, which has hit the planet in recent times, has also negative repercussions on indoor exercise and sports, due to social restrictions to deal with the contagion. In fact, closed environments favor the spread of the coronavirus and promote super diffusing events (Nishiura et al., 2020).

This situation generates general concern about the negative health implications of inactivity and sedentary behaviour (Hall et al., 2020).It is therefore of fundamental importance that the experts in physical and sports activities (D'Elia, 2020) develop increasingly innovative, engaging and effective training methods and practices to respond to clear needs for improvement and maintenance of health and performance as an alternative to the ordinary ones carried out at interior of indoor gyms. The training of professionals, in the motor and sports fields, must be oriented towards the development of curricula (D’Elia, 2019) that are more specific and applicable to historical contexts.Outdoor training, called outdoor training, is a very widespread training practice in recent times which, due to needs imposed by the epidemiological context of COVID 19 that has affected the entire planet, is developing in an increasingly organized manner. Various studies confirm that practicing physical 
or sporting activity outdoors can bring social, psychological and physiological benefits (Manferdelli et al., 2019; Eigenschenk et al., 2019). The outdoor environment provides a functional environment for social interaction (Leavell et al. 2019) and provides many benefits not available in controlled indoor environments (Brymer et al., 2014).

The various measures, adopted by individual national governments effectively suspend motor and sports activities in closed gyms, but allow outdoor training in compliance with precise rules of social distancing, as well as sports competitions without the presence of the public.

As a first response to this change in the social habits of practicing physical activity indoors in gyms, the professionals of physical activities and sports have developed innovative and original design ideas for outdoor training by proposing different physical disciplines for different classes of users. In our country, as in many others, the practice of outdoor training has begun to spread very quickly, but this practice has not shown the same level of participation in all contexts. The reasons could be numerous: from the lack of safe equipped spaces for training, the inexperience of the trainers, the fear of users.

Knowledge of the phenomenon at a national level is useful for analysing the evolution of general adaptations, but the data cannot be used to deal with the analysis of local data. Therefore, it is more useful to have the specific data referring to a single territory to understand local trends and opinions, as they differ from territory to territory. The problem is ignorance of the state of the art inherent in the adaptations and opinions of customers of physical activity and sports gyms as a result of the closure of indoor gyms. This knowledge, however, differs from territory to territory by type of social and environmental context, so the problem is limited to the area of interest and towards which the attention of indoor gyms is directed. The chosen area is that of the municipality of Fisciano in the province of Salerno where the users of the Studio Zen gym, which has about 100 customers, are affected. Aim is to quantify the level of participation in outdoor training activities organized in compliance with anti-COVID regulations. In particular, the focus of the survey is focused on the definition of the potential population of practitioners of the reference physical activities of the territory, the levels of motor and sports activity before the pandemic and, finally, the effects of the anti-COVID social restrictions on motor and sports activity.

\section{Materials and methods}

The study represents a fact-finding survey that, through the Cluster Analysis methodology, took place through the collection of data with the administration of a questionnaire drawn up via the Google Forms web survey platform. The questionnaire is made up of 22 questions distributed in three sections: the first section includes personal data, demographics and level of interest in psycho-physical well-being; the second section aims at understanding the level of motor and sporting activity before the gyms close, with particular reference to the objectives and frequency of training; the third section investigates the level of motor and sports activity after the closure of the gyms, with particular attention to the changes in the habits of the subjects both as regards the objectives and the weekly training frequency. Furthermore, the training activities most practiced during the closing period of the gyms have been identified.

The sample in question is represented by 76 subjects who usually use the Studio Zen gym to pursue various objectives: psycho-physical well-being, competitive performance, non-competitive performance, postural and functional rebalancing, etc.

\section{Procedure}

The sample was proposed to participate in the outdoor training activities organized by the structure.

These activities were organized following the request by the gym studio to the Municipality of Fisciano to be able to use the municipal spaces for the practice of physical and sporting activities outdoors in compliance with current regulations. The "Outdoor Workout" project approved by the same, which granted free public spaces from 21 July to 15 October 2020, was therefore presented to the offices of the municipality of Fisciano.

The project included courses in musical fitness, cross training, circuit training, Pilates and training for sportsmen, especially swimmers, footballers and volleyball players. A maximum of 10 people could participate in the training session, appropriately spaced. Two types of users participated: competitive and non-competitive sportsmen, mainly swimmers, and lovers of well-being who attended pilates, circuit training, functional training lessons.

At the end of this period, this sample was given the aforementioned questionnaire drawn up with Google Forms.

\section{Data analysis}

The analysis of the questionnaire responses provided important data on the composition of the sample and the levels of participation in outdoor training.

Overall, the study sample $(n=76)$ consisted of $64 \%$ females and $36 \%$ males. As shown in Figure 1 , the most represented age group is made up of those between 30 and 45 years of age, corresponding to $36 \%$, followed by the over 45 and 18 to 30 age groups, respectively representing the $25.3 \%$ and $24 \%$ of the sample; finally, the range between 14 and 18 years of age represents $14.7 \%$. 
Figure 1 - Age of the participants

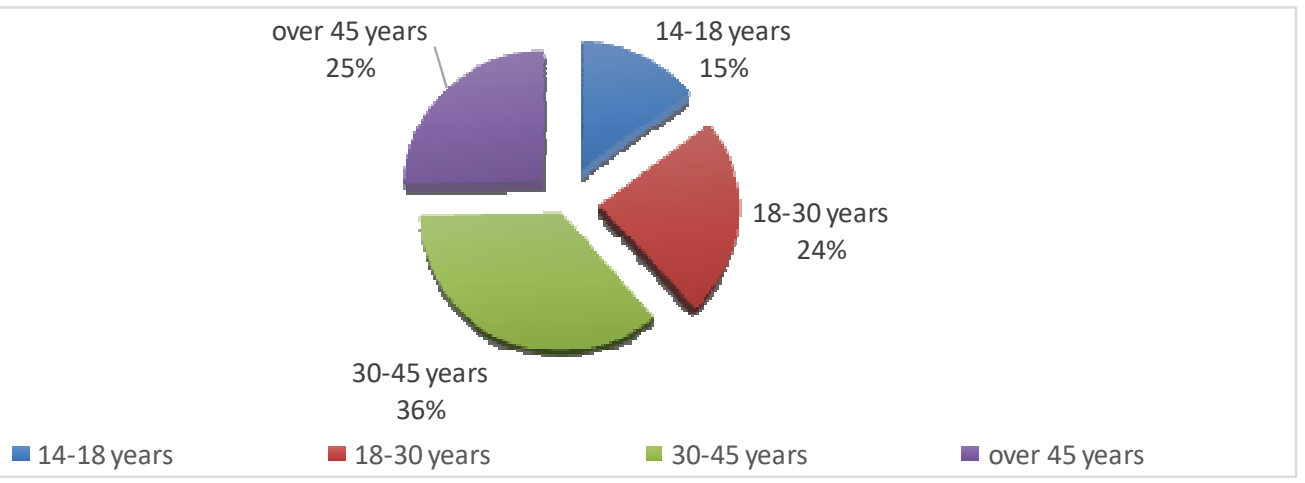

The data referring to the profession are very heterogeneous. A large part of interviewees is made up of students, over $22 \%$, housewives, $13.2 \%$, and office workers, $10.5 \%$, the remaining part is made up of shop assistants, freelancers, educators and sports technicians. $97.4 \%$ of the interviewees, at the time of the questionnaire reply, are in the Campania region, the remaining 2.6\% are in the Lazio region.

The data show that respondents attach great importance to the concept of well-being. On a scale of 0 to $5,73.7 \%$ of the sample answered 5 . More than $67 \%$ of the interviewees consider themselves normal weight, $30.3 \%$ consider themselves overweight, the remainder consider themselves underweight.

The second section of the questionnaire, concerning the levels of motor and / or sports activity before the closing of the gyms, provides information on the habits of the subjects interviewed in the period preceding the pandemic. As shown in figure 2, before the closure of the gyms, $96 \%$ of the interviewees practiced motor or sport activities regularly, distributed as follows: $51.3 \%$ carried out motor activity for well-being, $31.6 \%$ carried out non-competitive sporting activities (sporting activity that does not involve participation in federal competitions ), $13.2 \%$ carried out competitive sporting activity (sporting activity that involves participation in federal competitions) and $3.9 \%$ did not practice any motor or sport activity regularly.

Figure 2 - Training goals before gyms close

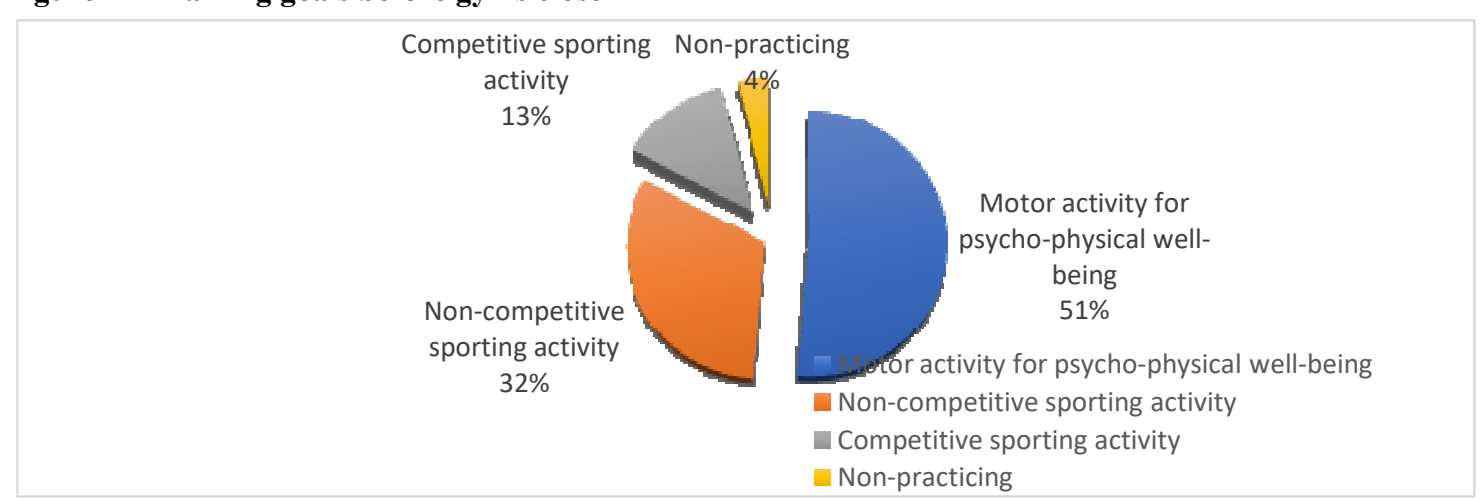

The weekly training frequency can be considered an important indicator of the level of motor and sports activity. Figure 3 shows that $47 \%$ of the interviewees, before the containment measures, exercised $3-4$ times a week, $32 \%$ carried out activities 1-2 times a week and, finally, 17\% trained for 5 or more times a week.

Figure 3 - Training goals before gyms close

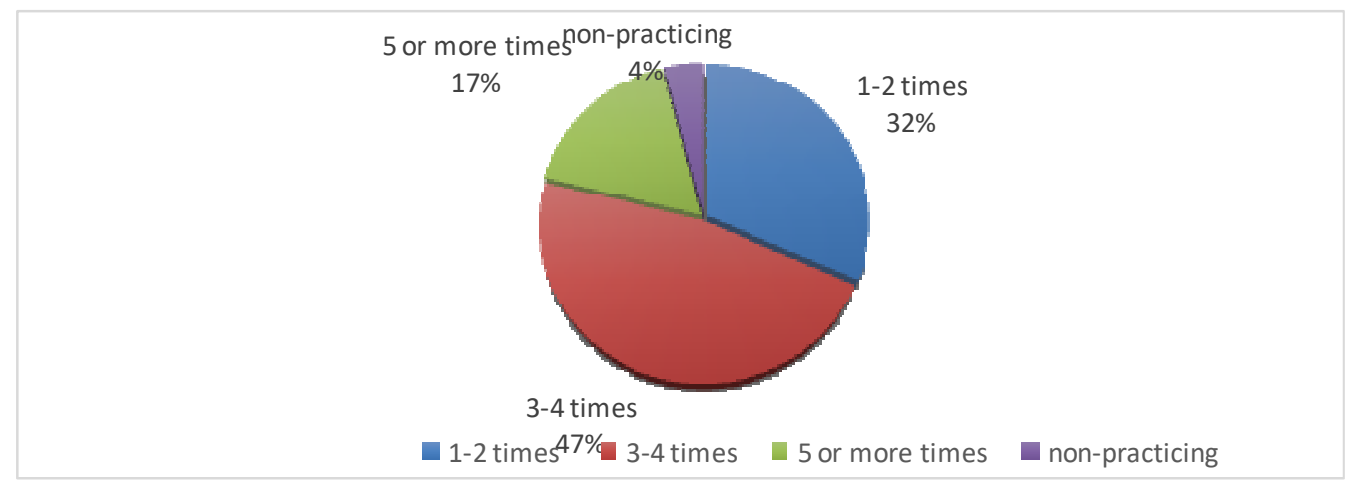




\section{GAETANO RAIOLA, FELICE DI DOMENICO}

The third section of the questionnaire focused on the levels of practice of motor and sports training after the closure of the gyms. As shown in the graph in Figure 3, the closure of the gyms has changed habits regarding the levels of practice and the objectives of motor and sports activity. The data shown by the figure 4 demonstratethat, at the closure of the gyms, the percentage of practicing physical or sporting activities fell to about $86 \%$ (before closing, the practitioners represented $96 \%$ of the sample). These subjects have organized themselves in various ways: at home or outdoors independently, at home or outdoors under the supervision of qualified technicians. There is a preference for activities carried out at home, which settles at $68 \%$, of which less than half with the help of online platforms and under the guidance of a qualified technician; $35.2 \%$ of the sample carried out training sessions outdoors, with a greater preference for activities led by qualified trainers, about $23 \% ; 13.2 \%$ did not carry out any training activity after the gyms closed.

Figure 4 - Changes between the period before and after the closing of the gyms

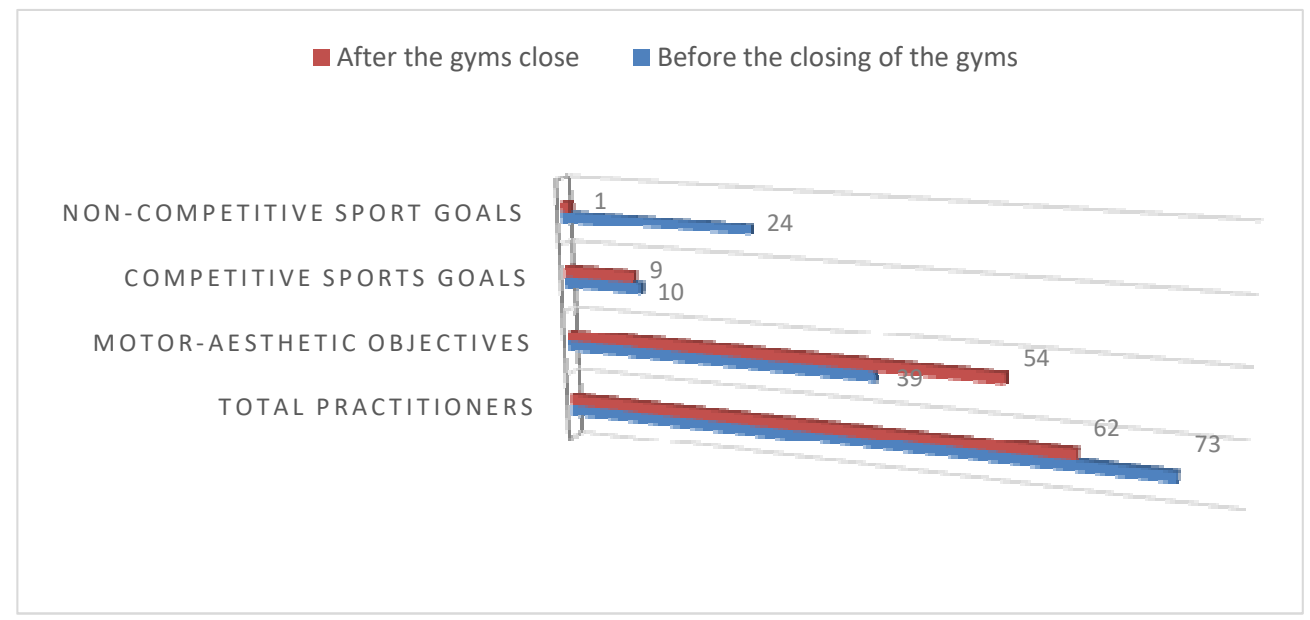

Motor activities for well-being were preferred by $71 \%$ of the sample, before the lockdown this percentage reached $51 \%$. The data also show a decrease in interest in competitive and non-competitive sports: $12.2 \%$ of the sample carried out competitive sports during the closing period of the gyms, down from the $13.2 \%$ recorded before the closure ; only $1.4 \%$ of the sample turned to non-competitive sports activities. This percentage, in the period before the closing, reached $31.6 \%$.

\section{Figure 5 - Training frequencies before and after the gyms close}

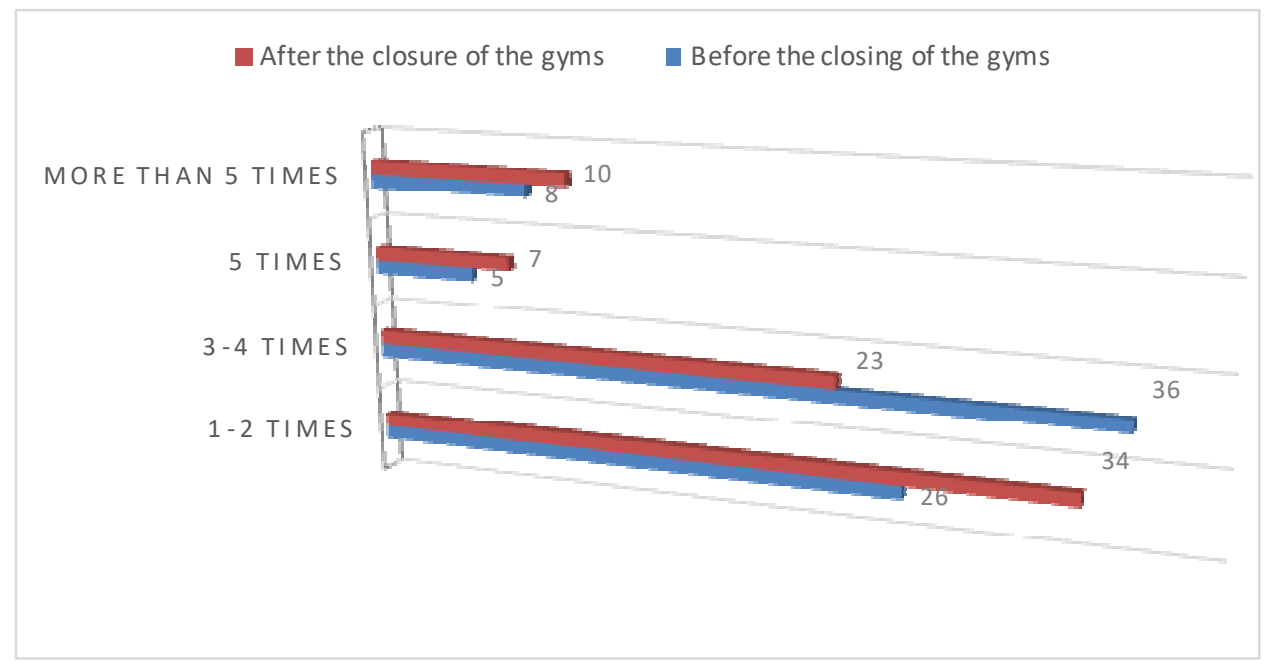

An important data is that relating to the weekly training frequency. Figure 5 shows that with the closure of the gyms, $51 \%$ of the interviewees practiced training activities with a frequency of $1-2$ times a week, a frequency which, before closing, was $34.2 \%$; on the other hand, the percentage referring to attendance 3-4 times a week decreased from $47.4 \%$ found in the pre-closure period to $31.1 \%$ found in the closure period. The changes for frequencies of 5 or more times a week are not relevant. The activities most practiced as part of the outdoor workout project were Pilates / yoga, which was attended by $37 \%$ of subjects, followed by bodyweight training, $26 \%$, and athletic and sports training, about $16 \%$. Finally, the reason why not all interviewees joined the project is asked. The responses showed that, although $93.7 \%$ of respondents knew what outdoor training was, $17.3 \%$ chose not to participate in this practice for various reasons. $15 \%$ of them say that the cause is to be attributed to 
their fear of contagion and $25 \%$ say they do not like training outdoors, the remaining part already did not train regularly before the gyms closed.

\section{Discussion}

The results show that, although almost all of the subjects continued to train through different methods after the closure of the gyms, only $35 \%$ of them did outdoor training. The remainder of the sample used other methods to train or did not train at all during the lockdown. Alternative methods to outdoor training are represented by independent training at home and online training. Among the reasons that led the subjects not to choose the practice of outdoor training as a valid alternative to training in the gym or not to train at all, the nonpreference towards this type of practice emerges, as even before the coronavirus emergency they did not use, and the feeling of fear of a possible contagion. The data show a greater preference for activities aimed at well-being, less demanding than sports activities, for various reasons that can be motivational, logistical and organizational. In fact, more low-impact activities are chosen without the use of tools such as Pilates and yoga, followed by freebody activities, running and walking, finally, athletic training activities for competitive and non-competitive sportsmen and women. cross training. A further important fact that emerged in the research is the tendency of subjects, during the lock down, to prefer motor activities to the detriment of sports activities.

\section{Conclusions}

It is believed that the objective has been achieved, as the levels of effectiveness of alternative proposals have been quantified in the territory under examination to meet the need to be able to train after the closure of the gyms to contain COVID 19. The outdoor training proposal in the context of this study did not have a high level of participation, most of the sample used home training as an alternative, either independently or with the guidance of a qualified technician using various video calling platforms or videoconference, the so-called "smart fitness" (Raiola et al., 2020). This trend could be reversed by movement professionals, through the development of increasingly safe and engaging training programs that lead to greater participation in outdoor training programs. A further data to be investigated and addressed following this study is that in reference to the decrease in the tendency to practice competitive and non-competitive sports. A motivation could be found in the different level of commitment between the two types of activities. Motor activity, aimed at achieving an acceptable level of psycho-physical well-being, is less demanding than sports activity.

Furthermore, the study laid the foundations for further investigations also on the national territory, in order to achieve an increasingly effective action to adequately respond to the growing demand for motor and sporting activity in normal and emergency conditions.

\section{References}

Aliberti, S., Invernizzi, P.L., Scurati, R., D’isanto, T. (2020) posture and skeletal muscle disorders of the neck due to the use of smartphones, journal of human sport and exercise, 15, pp. s586-s598.

Altavilla, G. (2020) Energetic cost in the different running conditions in team sport for the educational teaching method, Sport Science, 14 (1), pp. 17-20.

Altavilla, G. (2016). Relationship between physical inactivity and effects on individual health status. Journal of Physical Education and Sport, 16(Suppl. 2): 1069-1074). https://doi.org/10.7752/jpes.2016.s2170

Altavilla, G., D'Elia, F., Raiola, G. (2018) A breif review of the effects of physical activity in subjects with cardiovascular disease: An interpretative key, Sport Mont, 16 (3), pp. 103-106.

Andemberg M. (1973), Cluster analysis for applications, New York Academic Press

Booth, F.W.; Roberts, C.K.; Thyfault, J.P.; Ruegsegger, G.N.; Toedebusch, R.G. Role of inactivity in chronic diseases: Evolutionary insight and pathophysiological mechanisms. Physiol. Rev. 2017, 97, 1351-1402

Brymer, E ; Davids, K ; Mallabon, L. Comprendere i benefici per la salute psicologica e il benessere dell'attività fisica in natura: un'analisi delle dinamiche ecologiche. Ecopsicologia 2014 , 6, 189-197.

Cereda F. (2016), Physical and sports activities between the education of the person and the needs for health, Formazione\&Insegnamento XIV - 3 - 2016 ISSN 1973-4 778 print - 2279-7505

Ceruso, R., Esposito, G., D'elia, F. (2019a) Coordination attached to the qualitative aspects of football, Journal of Physical Education and Sport, 19, art. no. 260, pp. 1773-1776.

Ceruso, R., Esposito, G., D’Elia, F. (2019b) Analysis and evaluation of the qualitative aspects of the young players, Journal of Physical Education and Sport, 19, art. no. 266, pp. 1814-1819.

D'elia, F., D'isanto, T., Altavilla, G. (2019) Training and performance in the transition period, Journal of Human Sport and Exercise, 14 (Proc2), pp. S258-S262.

D'Elia, F. (2020) Teachers' perspectives about contents and learning aim of physical education in Italian primary school, Journal of Human Sport and Exercise, 15 (Proc2), pp. S279-S288.

D'elia, F. (2019) The core curriculum of university training to teach physical education in Italy, Journal of Physical Education and Sport, 19, art. no. 256, pp. 1755-1758

D'Elia, F., Tortella, P., Sannicandro, I., \& D'Isanto, T. (2020). Design and teaching of physical education for children and youth. Journal of Human Sport and Exercise, 15(4proc), S1527-S1533. 
D'Isanto, T. (2020) Test and assessment for improvement of the endurance in youth soccer, Journal of Human Sport and Exercise, 15 (Proc2), pp. S200-S205.

D'Isanto, T. (2016) Pedagogical value of the body and physical activity in childhood [Pedagoškavrijednosttijela $i$ tjelesneaktivnosti u djetinjstvu] Sport Science, 9, pp. 13-18.

Di Domenico, F., Fattore, S., D'isanto, T. (2019) The movement: Complexity and reductionism, evidence in comparison, Journal of Human Sport and Exercise, 14 (Proc4), pp. 1-8.

D'Isanto, T., D'Elia, F., Raiola, G., Altavilla, G. (2019) Assessment of sport performance: Theoretical aspects and practical indications, Sport Mont, 17 (1), pp. 79-82.

Eigenschenk B, Thomann A, McClure M, Davies L, Gregory M, Dettweiler U, Inglés E. Benefits of Outdoor Sports for Society. A Systematic Literature Review and Reflections on Evidence. Int J Environ Res Public Health. 2019 Mar 15;16(6):937. doi: 10.3390/ijerph16060937. PMID: 30875938; PMCID: PMC6466442.

Hall, G.; Laddu, D.R.; Phillips, S.A.; Lavie, C.J.; Arena, R. A tale of two pandemics: How will COVID-19 and global trends in physical inactivity and sedentary behavior affect one another? Prog. Cardiovasc. Dis. 2020

Lacharité-Lemieux, Marianne MSc 1,2 ; Brunelle, Jean-Pierre PhD 2 ; Dionne, Isabelle J. PhD 1,2 Adesione all'esercizio e risposte affettive, Menopausa: luglio 2015 - Volume 22 - Numero 7 - p 731-740 doi: 10.1097 / GME.0000000000000366

Izzo, R., Raiola, G., D’isanto, T., Cejudo, A., Giovanelli, G.M. (2020a) Modelling an adequate profile for a more targeted work methodology, with dedicated technologies, for elite-level footballers: Comparison between sub 17 vs sub 19, highlights and shadows, Sport Science, 13 (1), pp. 36-42.

Izzo, R., Altavilla, G., Cejudo, A., Raiola, G., D'Isanto, T., Giovannelli, M. (2020b)Performance improvement in yo-yo intermittent recovery test Level 2 and during official matches: The role of speed endurance training production in Élite football players, Sport Mont, 18 (3), pp. 61-66.

Izzo, R., D'isanto, T., Raiola, G., Cejudo, A., Ponsano, N., Varde'i, C.H. (2020c) The role of fatigue in football matches, performance model analysis and evaluation during quarters using live global positioning system technology at 50hz, Sport Science, 13 (1), pp. 30-35.

Izzo, R., Giovannelli, M., Raiola, G. Training load in elite goalkeepers with k-track for monitoring performance (2019a) Journal of Physical Education and Sport, 19, art. no. 280, pp. 1890-1896.

Izzo, R., Giovannelli, M., D'isanto, T. (2019b) The injury prevention program WTA functional primitive movement in professional football players: A case study, Journal of Physical Education and Sport, 19, art. no. 279, pp. 1885-1889.

Leavell MA, Leiferman JA, Gascon M, Braddick F, Gonzalez JC, Litt JS. Nature-Based Social Prescribing in Urban Settings to Improve Social Connectedness and Mental Well-being: a Review. Curr Environ Health Rep. 2019 Dec;6(4):297-308. doi: 10.1007/s40572-019-00251-7. PMID: 31713144.

Manferdelli G, La Torre A, Codella R. Outdoor physical activity bears multiple benefits to health and society. J Sports Med Phys Fitness. 2019 May;59(5):868-879. doi: 10.23736/S0022-4707.18.08771-6. Epub 2019 Jan 16. PMID: 30650943.

Nishiura H, Oshitani H., Kobayashi T., Saito T., Sunagawa T., Matsui T, Wakita T., MHL COVID-19 response Team, M. Suzuki, Closed environments facilitate secondary transmission of coronavirus disease 2019, medRxiv preprint (2020), https://doi.org/10.1101/2020.02.28.20029272.

Pellai A., Marzorati (2009) P. EDUCAZIONE ALLA SALUTE. Standard e linee guida dalla scuola elementare alla scuola superiore. Franco Angeli

Raiola, G. Motor learning and teaching method(2017) Journal of Physical Education and Sport, 17, art. no. 236, pp. 2239-2243.

Raiola, G., Aliberti, S., Esposito, G., Altavilla, G., D’Isanto, T., \& D’Elia, F. (2020). How has the Practice of Physical Activity Changed During the COVID-19 Quarantine? A Preliminary Survey. Teoriâ ta MetodikaFìzičnogoVihovannâ, 20 (4), 242-247

Waddington I. (2010), Physical activity, movement, sport and health. What is the correct public health message? Sociologia e politichesociali, pp. 13-27, DOI:10.3280/SP2010-002002

Sannicandro, I. (2020). Ecological dynamics approach in the youth soccer: A short narrative review. Journal of Human Sport and Exercise, 15(4proc), S1133-S1139. doi:https://doi.org/10.14198/jhse.2020.15.Proc4.14

Sannicandro, I. (2017) Effects of strength and core stability training versus strength and aerobic training in subjects aged over 65, Medicinadello Sport, 70 (4), pp. 410-418.

Sannicandro, I., Spedicato, M., Palaia, G., Cofano, G., Bisciotti, G.N., Eirale, C. (2015) Strength ability, endurance and anthropometric parameters in youth football: Descriptive analysis and functional relationships, Medicinadello Sport, 68 (1), pp. 19-30.

Sannicandro, I. (2011) Evaluation of muscle strength in young and top-level soccer players Medicinadello Sport, 64 (1), pp. 9-20.

Sannicandro, I., Colella, D., Rosa, R.A., Manno, R. (2008) Modulation of motor load in old people: Effect of different exercise training protocols on power flexibility, Medicinadello Sport, 61 (4), pp. 443-454. 